\title{
ANALISIS ANTRIAN DENGAN MODEL SINGLE CHANNEL SINGLE PHASE SERVICE PADA STASIUN PENGISIAN BAHAN BAKAR UMUM (SPBU) I GUSTI NGURAHRAI PALU
}

\author{
1D. Nurfitria, ${ }^{2}$ Nur'Eni, dan 3I.T. Utami \\ 1,2,3Program Studi Matematika Jurusan Matematika \\ Fakultas Matematika dan IImu Pengetahuan Alam Universitas Tadulako \\ Jalan Soekarno-Hatta Km. 9 Palu 94118, Indonesia \\ 1defitanurfitria30@gmail.com,2² enyocy@yahoo.com,33 Triutami.iut@gmail.com
}

\begin{abstract}
A queue is a line of customers who need services from one or more services. The queue problems related to the efficiency, where the queue will reduce convenience the service to the customers. This also happened SPBU I Gusti Ngurahrai, a queue happened because the service faciliti not comparable with the rate of the arrival of customers. The researchers are interested to analyze the queue in SPBU using the model of the Single ChannelSingle Phase. From the results of research with the use of the theory of a queue analysis shows that the characteristics of a queue obtained average been queuing up in the system $\left(L_{s}\right)$ is 9 people, the average queuing in queue $\left(\mathrm{L}_{\mathrm{a}}\right)$ is 8 people while opportunities for the number of customers in queue $\left(\mathrm{P}_{\mathrm{n}}\right)$ is $4.3 \%$. The average waiting time in the system $\left(\mathrm{W}_{\mathrm{s}}\right)$ is 8 minutes while the average waiting time in a queue $\left(\mathrm{W}_{\mathrm{a}}\right)$ is a about 7 minutes, the level of server downtime $(\mathrm{K})$ is $89 \%$ while the unemployment rate server $(\mathrm{W})$ is $10 \%$, so the total cost by the SPBU Rp. 246.250.000,00. In case the cost and time wait after the adding of one unit server, the service will be optimal with additional cost as much Rp.422.500.000,00 and the average waiting time the system $\left(\mathrm{W}_{\mathrm{s}}\right)$ is 1 minutes while the average waiting time in a queue $\left(\mathrm{W}_{\mathrm{a}}\right)$ will be reduced to 0,289 minutes.
\end{abstract}

Keywords : : Characteristics, Single Channel - Single Phase Service, The Queue.

\section{ABSTRAK}

Antrian adalah suatu garis tunggu dari pelanggan yang memerlukan layanan dari satu atau lebih pelayanan. Masalah antrian berhubungan dengan efisiensi, dimana terjadinya antrian akan mengurangi kenyamanan pelayanan kepada pelanggan. Hal ini juga terjadi di SPBU I Gusti Ngurahrai, antrian terjadi karena banyaknya fasilitas pelayanan tidak sebanding dengan laju kedatangan pelanggan. Sehingga peneliti tertarik untuk menganalisis antrian di SPBU tersebut dengan menggunakan model Single Channel - Single Phase. Dari hasil penelitian dengan menggunakan analisis teori antrian menunjukkan bahwa karakteristik antrian diperoleh ratarata antri dalam sistem $\left(L_{s}\right)$ sebesar 9 orang, rata-rata antri dalam antrian $\left(L_{a}\right)$ sebesar 8 orang sedangkan peluang terjadinya jumlah pelanggan dalam antrian $\left(P_{n}\right)$ sebesar $4,3 \%$. Rata-rata waktu menunggu dalam sistem $\left(W_{s}\right)$ adalah sebesar 8 menit sedangkan rata-rata waktu menunggu dalam antrian $\left(W_{a}\right)$ adalah sebesar 7 menit, tingkat kesibukan server $(\mathrm{K})$ adalah sebesar $89 \%$ sedangkan tingkat pengangguran server $(\mathrm{W})$ adalah sebesar 
$10 \%$, sehingga total biaya yang harus dikeluarkan oleh pihak SPBU sebesar RP. 246.250.000,00. Biaya dan waktu menunggu setelah penambahan satu unit server, pada proses antrian di SPBU tersebut agar pelayanannya menjadi optimal adalah sebesar Rp. 422.500.000,00 dan rata-rata waktu menunggu dalam sistem $\left(W_{s}\right)$ adalah sebesar 1 menit sedangkan rata-rata waktu menunggu dalam antrian $\left(W_{a}\right)$ adalah sebesar 0,289 menit.

Kata Kunci : Antrian, Karakteristik, Single Channel-Single Phase Service.

\section{PENDAHULUAN}

\subsection{Latar Belakang Penelitian}

Antrian adalah sebuah aktifitas dimana konsumen menunggu untuk memperoleh layanan. Antrian timbul disebabkan oleh kebutuhan akan layanan melebihi kemampuan kapasitas pelayanan atau fasilitas pelayanan, sehingga pengguna fasilitas yang tiba tidak bisa segera mendapatkan layanan (Kakiav, Thomas J., 2004). Kehidupan manusia yang serba cepat menuntut segala sesuatu untuk bersifat efekif.

Pemakaian waktu seminim mungkin merupakan hal yang penting untuk diperhatikan oleh setiap penyedia jasa layanan. Semua pelanggan sangat menghargai waktu karena merupakan sesuatu yang penting dalam kehidupan, sehingga selalu menginginkan sistem optimal yang dapat memberikan pelayanan yang baik. Antrian terbentuk jika banyaknya yang akan dilayani melebihi kapasitas layanan yang tersedia. Antrian yang terlalu panjang akan mengakibatkan kehilangan pelanggan. Akibatnya, permasalahan muncul karena terlalu banyak permintaan (pelanggan terlalu lama menunggu) dan terlalu sedikit permintaan (terlalu banyak waktu menganggur).

Kegiatan antrian sering terjadi di beberapa tempat yang membutuhkan pelayanan yang besar sedangkan fasilitas pelayanannya kurang. Salah satu tempat terjadinya kasus antrian yaitu SPBU 74.942.09 yang terletak di Jalan I Gusti Ngurahrai Palu. SPBU tersebut menyediakan satu fasilitas pengisian bahan bakar untuk pengendara motor, dengan jenis bahan bakar premium. Pada satu fasilitas ini terdapat satu jalur, sehingga dapat mengurangi masalah antrian ketika pelanggan datang pada saat tertentu untuk mengisi bahan bakar kendaraan bermotor. Namun, seiring dengan kemajuan jaman yang menyebabkan pengguna sepeda motor saat ini mengalami peningkatan pelanggan ingin memenuhi kebutuhan akan bahan bakar pada saat-saat tertentu dapat menyebabkan masalah antrian, karena jumlah fasilitas yang kurang untuk memenuhi pelayanan pelanggan. Akibat dari kurang optimalnya pelayanan pada antrian tersebut yaitu, terlihat beberapa konsumen merasa kurang nyaman karena antrian yang panjang. 
Mencegah timbulnya antrian atau mengurangi antrian yang panjang adalah dengan menganalisis sistem antrian SPBU I Gusti Ngurahrai dengan menerapkan metode statistik yaitu teori antrian. Penelitian dilakukan pada saat dimana antrian yang panjang terjadi pada pagi hari selama lima hari dari jam 09.00 - 11.00 bertujuan agar keputusan yang diambil dari hasil analisis dapat berlaku untuk berbagai kondisi pelayanan, sehingga analisis dapat memberikan masukan yang bermanfaat untuk menyelesaikan masalah dengan lebih optimal.

Pada penelitian ini peneliti menggunakan model Single Channel Single Phase Service di SPBU I Gusti Ngurahrai Palu karena SPBU I gusti Ngurahrai Palu hanya memiliki satu jalur pelayanan. Model Single Channel Single Phase Service merupakan model pelayanan yang hanya ada satu jalur yang memasuki sistem pelayanan dan ada satu pelayanan saja.

\subsection{Rumusan Masalah}

Berdasarkan latar belakang di atas, maka pokok permasalahan yang dikemukakan dalam penelitian ini adalah :

1. Bagaimana menghitung karateristik dari model antrian Single Channel Single Phase Service di SPBU I Gusti Ngurahrai Palu yang meliputi :

- Peluang terjadinya jumlah pelanggan dalam antrian $\left(P_{n}\right)$.

- Rata-rata yang antri dalam sistem $\left(L_{s}\right)$.

- Rata-rata yang antri dalam antrian $\left(L_{a}\right)$.

- Rata-rata waktu menunggu dalam sistem $\left(W_{s}\right)$.

- Rata-rata waktu menunggu dalam antrian $\left(W_{a}\right)$.

- Tingkat Kesibukan Kasir (K)

- Tingkat pengangguran kasir (W).

2. Berapa total biaya yang diperlukan di SPBU I Gusti Ngurahrai Palu agar pelayanannya menjadi optimal?

\subsection{Tujuan Penelitian}

Adapun tujuan yang ingin dicapai adalah sebagai berikut:

1. Menentukan karateristik dari model antrian Single Channel Single Phase Service di SPBU I Gusti Ngurahrai Palu yang meliputi :

- Peluang terjadinya jumlah konsumen dalam antrian $\left(P_{n}\right)$.

- Rata-rata yang antri dalam sistem $\left(L_{s}\right)$. 
- Rata-rata yang antri dalam antrian $\left(L_{a}\right)$.

- Rata-rata waktu menunggu dalam sistem $\left(W_{s}\right)$.

- Rata-rata waktu menunggu dalam antrian $\left(W_{a}\right)$.

- Tingkat Kesibukan Server (K)

- Tingkat pengangguran Server (W).

2. Total biaya yang diperlukan di SPBU I Gusti Ngurahrai Palu agar pelayanannya menjadi optimal.

\subsection{Manfaat Penelitian}

Manfaat yang diharapkan dalam penelitian ini adalah:

1. Memberikan solusi agar konsumen yang datang tentunya tidak terlalu lama menunggu.

2. Sebagai bahan masukan sekaligus pembanding bagi pihak SPBU yang memerlukan informasi mengenai sistem antrian khususnya dalam menentukan jasa layanan pada setiap server yang diperlukan untuk melayani konsumen yang datang.

3. Penelitian ini sebagai sarana untuk melatih penulis dan menambah pengetahuan untuk menganalisa fenomena antrian yang terjadi di masyarakat.

\subsection{Ruang Lingkup Penelitian}

Ruang lingkup penelitian ini mengemukakan tentang :

1. Variabel-variabel yang diteliti yaitu berupa variabel dari waktu kedatangan konsumen dan variabel dari waktu pelayanan server

2. Waktu pengambilan data pada pagi hari selama 5 hari dari jam $09.00-11.00$.

3. Khusus Pengendara bermotor

4. Karakteristik yang terdapat dalam analisis sistem antrian dihitung dengan menggunakan model antrian Single Channe/ Single Phase Service.

\section{METODE PENELITIAN}

\subsection{Jenis dan Sumber Data}

Jenis data yang digunakan adalah data kuantitatif, yaitu berupa angka data waktu kedatangan dan data waktu pelayanan dengan sumber data yang digunakan dalam penelitian ini berupa data primer, yaitu data yang diambil langsung dari objek penelitian.

Penelitian ini menggunakan data yang didapatkan melalui observasi pada SPBU 74.942.09 di Jalan I Gusti Ngurahrai Palu. Pengamatan dilakukan pada pagi hari selama 5 
hari selama 2 jam, pukul 09.00 - 11.00 WITA, untuk memperoleh data waktu kedatangan pelanggan dan waktu pelayanan. Adapun prosedur penelitian adalah sebagai berikut:

1. Pengumpulan Data

2. Uji waktu antar kedatang dengan menggunakan uji Kolmogorov smirnov

3. Uji pelayanan dengan menggunakan uji Runtun

4. Menentukan Karakteristik Antrian

5. Kesimpulan

\subsection{Jenis Antrian}

Jenis antrian dalam kehidupan sehari-hari ada beberapa model yaitu:

2.2.1. Jalur Tunggal Dengan Satu Tahap Pelayanan

Single Channel berarti bahwa hanya ada satu jalur untuk memasuki sistem pelayanan atau ada satu pelayanan. Single phase menunjukkan bahwa hanya ada satu stasiun pelayanan sehingga yang telah menerima pelayanan dapat langsung keluar dari sistem antrian.

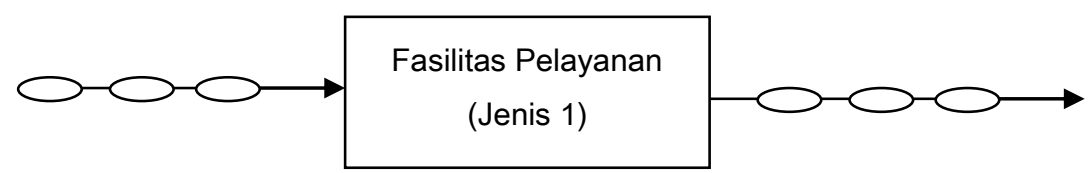

\section{Gambar 1 :Single Chanel-Single Phase Service}

\subsubsection{Jalur Tunggal Beberapa tahap Pelayanan}

Single Channel Multi Phase Service atau jalur tunggal beberapa tahap pelayanan yaitu sistem antrian yang hanya ada satu jalur antrian namun ada dua atau lebih pelayanan yang dilaksanakan secara berurutan.

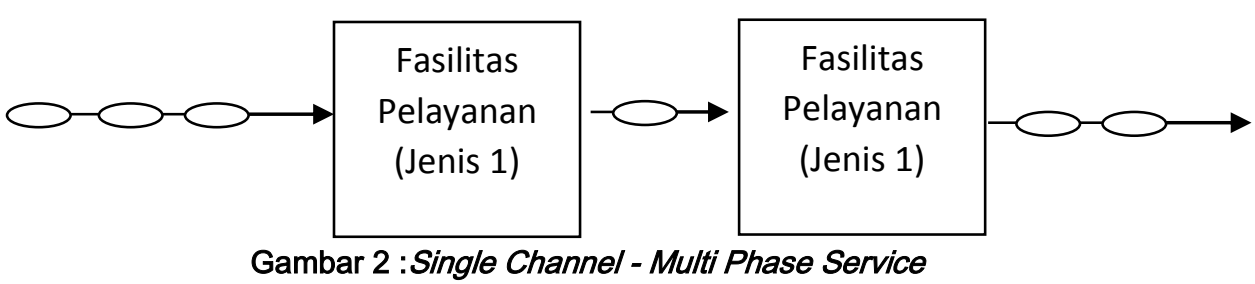

\subsubsection{Jalur Ganda Satu tahap Pelayanan}

Multiple Channel Single Phase Service atau jalur ganda satu tahap pelayanan yaitu sistem yang hanya terdapat satu jalur antrian dengan dua ataulebih fasilitas pelayanan. 


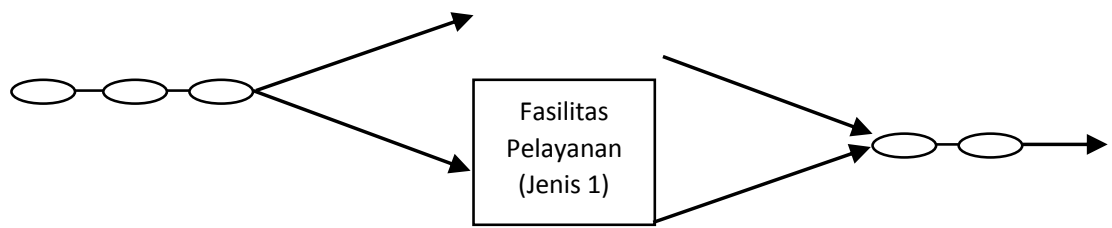

Gambar 3 : Multi Channel - Single Phase Service

\subsubsection{Jalur Ganda Beberapa Tahap Pelayanan}

Multiple Channel Multi Phase Service atau jalur ganda beberapa tahap pelayanan yaitu system yang terdapat beberapa jalur antrian dengan beberapa tahap pelayanan.

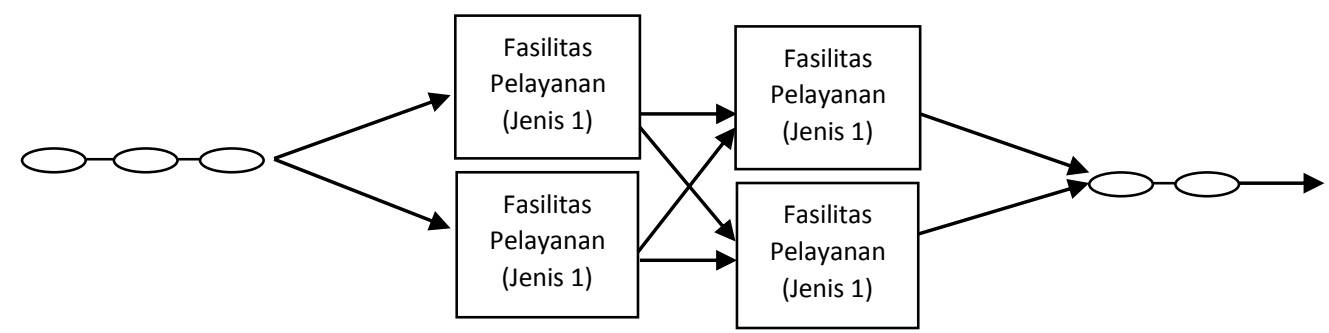

Gambar 4 : Multi Channel - Multi Phase Service

(Subagyo, P. dkk., 2000)

Pada penelitian ini model antrian yang digunakan adalah Single Channel Single Phase Service atau antrian jalur tunggal dengan satu tahap pelayanan.

\section{HASIL DAN PEMBAHASAN}

\subsection{Analisis Data}

Untuk proses analisis data yang digunakan peneliti yaitu dengan menggunakan Uji Kolmogorov smirnov satu sampel dan uji runtun. Waktu antar kedatangan akan diuji apakah berdistribusi Eksponensial atau tidak dengan menggunakan Statistik Uji Kolmogorov Smirnov Satu Sampel dan waktu pelayanan akan diuji apakah bersifat acak atau tidak dengan menggunakan program SPSS 12.0 for Windows.

\subsubsection{Uji Kolmogorov Smirnov Satu Sampel}

Statistik Uji kolmogorov Smirnov satu sampel digunakan untuk menguji data waktu antar kedatangan apakah berdistribusi Eksponensial atau tidak, dengan menggunakan program SPSS 12.0 for Windows. Dengan langkah-langkah sebagai berikut : Djarwanto,1995) 
1. Waktu antar kedatangan akan diuji apakah berdistribusi Eksponensial atau tidak melalui hipotesis pengujian :

$\mathrm{H}_{0}: \mu_{0}=\mu$ waktu antar kedatangan mengikuti distribusi Eksponensial

$\mathrm{H}_{1}: \mu_{0} \neq \mu$ waktu antar kedatangan tidak mengikuti distribusi Eksponensial

2. Adapun rumus Kolmogorov Smirnov yang digunakan dalam penelitian adalah

$\mathrm{D}=$ Maks $\left|\mathrm{F}_{\mathrm{a}}(\mathrm{X})-\mathrm{F}_{\mathrm{e}}(\mathrm{X})\right|$

3. Taraf Signifikan

Digunakan Taraf signifikan $5 \%$ atau 0,05

4. Kriteria Pengujian

$\mathrm{H}_{0}$ diterima apabila Kolmogorov Smirnov Hitung $\leq$ Kolmogorov Smirnov Tabel.

$\mathrm{H}_{0}$ ditolak apabila Kolmogorov Smirnov Hitung > Kolmogorov Smirnov Tabel.

5. Hasilnya disajikan sebagai berikut

Tabel 5 Hasil Uji Kecocokan Distribusi Waktu Antar Kedatangan menggunakan program SPSS 12.0 for Windows

\begin{tabular}{|l|l|l|}
\hline \multicolumn{2}{|l|}{ One-Sample Kolmogorov-Smirnov Test } \\
\hline \multicolumn{2}{|l|}{} & WaktuAntarKedatangan \\
\hline $\mathrm{N}$ & 708 \\
\hline $\begin{array}{l}\text { Exponential } \\
\text { parameter. }{ }^{\mathrm{a}, \mathrm{b}}\end{array}$ & Mean & 52,2546 \\
\hline $\begin{array}{l}\text { Most } \\
\text { Extreme } \\
\text { Differences }\end{array}$ & Absolute & .039 \\
\cline { 2 - 3 } & Positive & .039 \\
\hline Kolmogorov-Smirnov $\mathrm{Z}$ & 1,025 \\
\hline Asymp. Sig. (2-tailed) & .245 \\
\hline a. Test Distribution is Exponential. \\
\hline b. Calculated from data. \\
\hline
\end{tabular}

6. Keputusan

Dari Tabel 1 hasil pengujian di atas diperoleh nilai simpangan positif $\left(\mathrm{D}^{+}\right)$adalah 0,039 dan simpangan negatifnya sebesar $-0,022$. Sehingga nilai statistik Uji Kolmogorov Smirnov Satu Sampel adalah nilai simpangan terbesar (absolute) yaitu 0,039 dan nilai peluangnya adalah 0,245 . Karena nilai peluangnya lebih besar dari taraf signifikan 0,05 maka dapat disimpulkan $\mathrm{H}_{0}$ diterima yang artinya bahwa waktu antar kedatangan mengikuti distribusi Eksponensial. 


\subsubsection{Uji Runtun}

Statistik uji runtun digunakan untuk menguji data waktu pelayanan apakah bersifat acak atau tidak dengan menggunakan program SPSS 12.0 for Windows. Dengan Langkah-langkah sebagai berikut

1. Waktu pelayanan akan diuji apakah mengikuti distribusi Poisson atau tidak melalui hipotesis pengujian

$\mathrm{H}_{0}: \mu_{0}=\mu$ waktu pelayanan bersifat acak

$\mathrm{H}_{1}: \mu_{0} \neq \mu$ waktu pelayanan tidak bersifat acak

2. Taraf Signifikan

Digunakan taraf signifikan $5 \%$ atau 0,05

3. Kriteria Pengujian

$$
\begin{aligned}
& \mathrm{H}_{0}: \mu_{0}=\mu \text { diterima apabila }-Z_{\alpha / 2} \leq Z \leq Z_{\alpha / 2} \\
& H_{1}: \mu_{0} \neq \mu \text { ditolak apabila } Z>Z_{\alpha / 2} \text { atau } Z<-Z_{\alpha / 2}
\end{aligned}
$$

4. Hasilnya disajikan sebagai berikut

Tabel 6 Hasil Uji Kecocokan Distribusi Waktu Kedatangan menggunakan program SPSS

\begin{tabular}{|c|c|}
\hline \multicolumn{2}{|l|}{ Runs Test } \\
\hline & $\begin{array}{l}\text { Waktu } \\
\text { Pelayanan }\end{array}$ \\
\hline Test Value ${ }^{a}$ & 37,00 \\
\hline Cases < Test Value & 353 \\
\hline Cases $>=$ Test Value & 355 \\
\hline Total Cases & 708 \\
\hline Number of Runs & 354 \\
\hline Z &,- 075 \\
\hline Asymp. Sig. (2-tailed) & ,940 \\
\hline a. Median & \\
\hline
\end{tabular}
12.0 for Windows

\section{Keputusan}

Berdasarkan Tabel 2 hasil pengujian dapat dilihat bahwa banyaknya Runs sebanyak 354 dan nilai statistik uji $Z$ sebesar - 0,075 dengan nilai peluangnya adalah 0,940. Karena nilai peluangnya lebih besar dari taraf signifikan 0,05 maka dapat disimpulkan untuk menerima $\mathrm{H}_{0}$ yang artinya bahwa waktu kedatangan bersifat acak. 


\subsection{Hasil Keseluruhan Analisis Model Antrian Jalur Tunggal Dengan Satu Tahap Pelayanan Dari Pukul 09.00-11.00}

Berdasarkan hasil pengamatan yang dilakukan pada hari kamis 2 April 2015 sampai hari Senin tanggal 6 April 2015 diperoleh :

DIK :

$\mathrm{N}: 708$ orang

Jumlah waktu antar kedatangan $=36736$

Jumlah waktu Pelayanan $=33083$

$\lambda=\frac{\mathrm{N}}{\text { jumlah waktu antar kedatangan }}$

$\mu=\frac{\mathrm{N}}{\text { jumlah pelayanan }}$

Jadi rata-rata tingkat kedatangan konsumen $(\lambda)$ untuk 708 orang adalah 0,0193 detik dan rata-rata tingkat pelayanan $(\mu)$ adalah 0,0214 detik. Dari nilai tersebut dapat diketahui nilai untuk karakeristik model antrian jalur tunggal dengan satu tahap pelayanan yang meliputi :

- $\quad$ Rata-Rata Yang Antri Dalam Sistem $\left(\mathbf{L}_{\mathbf{s}}\right)$

Rata-rata orang yang antri dalam sistem menggunakan rumus pada persamaan (4) yaitu :

$\mathrm{L}_{\mathrm{s}}=\frac{\lambda}{\mu-\lambda}$

Ket : $L_{s}=$ Rata-rata yang antri dalam sistem

$\lambda=$ Tingkat kedatangan

$\mu=$ Tingkat pelayanan

Nilai $L_{\mathrm{s}}$ sebesar 9,19 berarti bahwa rata-rata pelanggan berada dalam sistem antrian sebanyak 9 orang

- $\quad$ Rata-Rata Yang Antri Dalam Antrian $\left(\mathrm{L}_{\mathrm{a}}\right)$

Rata-rata orang yang antri dalam antrian menggunakan rumus pada persamaan (5) yaitu

$\mathrm{L}_{\mathrm{a}}=\frac{\lambda^{2}}{\mu(\mu-\lambda)}$

Nilai $L_{a}$ sebesar 8,23 berarti bahwa rata-rata pelanggan berada dalam antrian sebanyak 8 orang.

- $\quad$ Peluang Terjadinya Jumlah Pelanggan Dalam Antrian $\left(\mathrm{P}_{\mathrm{n}}\right)$.

Peluang terjadinya jumlah pelanggan dalam antrian $\left(\mathrm{P}_{\mathrm{n}}\right)$ menggunakan rumus pada persamaan (6) yaitu : 
$\mathrm{P}_{\mathrm{n}}=\left(\frac{\lambda}{\mu}\right)^{\mathrm{n}}\left(1-\left(\frac{\lambda}{\mu}\right)\right)$

Dik : $n=1$ (Banyaknya orang yang antri dalam antrian, yang mana nilai tersebut diperoleh dari nilai $\mathrm{L}_{\mathrm{a}}$ ).

Nilai $\mathrm{P}_{\mathrm{n}}$ di atas bisa diartikan bahwa kemungkinan jumlah orang yang antri sebesar 0,0421 atau dengan kata lain sebesar $4,21 \%$.

- $\quad$ Rata-Rata Waktu Menunggu Dalam Sistem $\left(\mathrm{W}_{\mathrm{s}}\right)$.

Rata-rata waktu orang yang menunggu dalam sistem menggunakan rumus pada persamaan (7) yaitu :

$\left(\mathrm{W}_{\mathrm{s}}\right)=\frac{1}{\mu-\lambda}$

Nilai $\mathrm{W}_{\mathrm{s}}$ sebesar 476,19 detik menunjukkan bahwa waktu rata-rata menunggu dalam sistem yaitu \pm 8 menit.

- $\quad$ Rata-Rata Waktu Menunggu Dalam Antrian $\left(\mathrm{W}_{\mathrm{a}}\right)$.

Rata-rata waktu orang yang menunggu dalam antrian menggunakan rumus pada persamaan (8) yaitu sebagai berikut :

$\left(\mathrm{W}_{\mathrm{a}}\right)=\frac{\lambda}{\mu(\mu-\lambda)}$

Nilai $\mathrm{W}_{\mathrm{a}}$ sebesar 429,46 detik menunjukkan bahwa waktu rata-rata menunggu dalam antrian yaitu \pm 7 menit.

- $\quad$ Tingkat Kesibukan Server (K)

Tingkat kesibukan server dapat diperoleh dengan menggunakan rumus yang ada pada persamaan (9) yaitu sebagai berikut :

$\mathrm{K}=\frac{\lambda}{\mu}$

Jadi, tingkat Kesibukan server $(\mathrm{K})$ adalah \pm sebesar $90,18 \%$

- $\quad$ Tingkat Pengangguran Server (W)

Tingkat pengangguran server menggunakan rumus pada persamaan (10) yaitu sebagai berikut :

$\mathrm{W}=100 \%-\mathrm{K}$

Jadi, tingkat pengangguran server $(W)$ adalah \pm sebesar $9,82 \% \approx 10 \%$.

\subsection{Analisis Biaya Untuk Satu Unit Server}


Analisis biaya yang dihitung berdasarkan pada nilai dari hasil keseluruhan analisis model antrian jalur tunggal dengan satu tahap pelayanan dari pukul 09.00-11.00 sehingga diperoleh :

- Total biaya menunggu $\left(\mathrm{E}\left(\mathrm{C}_{\mathrm{w}}\right)\right)$ yaitu sebagai berikut

Dik : Gaji Server $=$ Rp. 1.750 .000

Rata-rata pelanggan dalam sistem antrian $\left(n_{t}\right)=L_{s} \times 2$ jam $\times 30$ hari $=540$ orang

Biaya Menunggu $\left(c_{\mathrm{w}}\right)=$ gaji server $x$ tingkat pengangguran server $=$ Rp. 175.000 $E\left(C_{w}\right)=n_{t} X c_{w}=R p .94 .500 .000 /$ bulan

- Total biaya pelayanan $\left(\mathrm{E}\left(\mathrm{C}_{\mathrm{s}}\right)\right)$ yaitu sebagai berikut :

Dik : Biaya pembuatan satu server $=$ Rp. 150.000 .000 .

$$
\begin{aligned}
\mathrm{s} & =1 \text { unit server } \\
\mathrm{C}_{\mathrm{S}} & =\text { Rp. } 151.750 .000
\end{aligned}
$$

$\mathrm{E}\left(\mathrm{C}_{\mathrm{s}}\right)=\mathrm{s}\left(\mathrm{C}_{\mathrm{s}}\right)=151.750 .000 /$ bulan

- Total biaya keseluruhan $\left(\mathrm{E}\left(\mathrm{C}_{\mathrm{t}}\right)\right)$ sebagai berikut :

$$
\mathrm{E}\left(\mathrm{C}_{\mathrm{t}}\right)=\mathrm{E}\left(\mathrm{C}_{\mathrm{w}}\right)+\mathrm{E}\left(\mathrm{C}_{\mathrm{s}}\right)=\text { Rp. } 246.250 .000
$$

Jadi total biaya operasional pihak SPBU I Gusti Ngurahrai Palu adalah sebesar Rp. 246.250.000,00. Dengan total biaya seperti antrian yang terjadi masih belum bisa diatasi. Untuk itu apabila pihak perusahaan melakukan penambahan satu unit server kerugian yang diperoleh akan semakin berkurang.

\subsection{Perhitungan analisis biaya pada sistem antrian dengan melakukan penambahan server}

Perhitungan analisis biaya yang akan digunakan untuk mencegah terjadinya proses antrian di SPBU I gusti Ngurahrai Palu dibagian bahan bakar untuk pengendara motor, dengan jenis bahan bakar Premium yaitu dengan melakukan penambahan satu unit server. Akan tetapi untuk melakukan perhitungan dengan melakukan penambahan server otomatis model antrian yang terjadi akan berubahan menjadi model antrian jalur ganda, satu tahap pelayanan. Analisis antrian jalur ganda, satu tahap pelayanan akan dihitung jika

Dik : $N=708$ orang

Jumlah waktu antar kedatangan $=36736$

Jumlah waktu Pelayanan $=33083$

$\lambda=0,0193$ 


$$
\mu=0,0214 \text {. }
$$

$s=2$ Jumlah Server (2 unit)

* Menghitung nilai peluang tidak ada pelanggan yang antri rumusnya adalah

$$
\mathrm{P}_{0}=\frac{1}{\left.\left[\sum_{\mathrm{n}=0_{\mathrm{n} !}-\frac{1}{\mu}}^{\mathrm{n}}\right)^{\mathrm{n}}\right]+\frac{1}{\mathrm{~s} !}\left(\frac{\lambda}{\mu}\right)^{\mathrm{s}} \frac{\mathrm{s} \mu}{\mathrm{s} \mu-\lambda}}
$$

Nilai peluang tidak ada pelanggan yang antri adalah sebesar 0,549 atau 54,9\%.

Rata-rata pelanggan yang antri dalam antrian $\left(\mathrm{L}_{\mathrm{a}}\right)$ rumusnya yaitu

$L_{a}=\frac{\left(\frac{\lambda}{\mu}\right)^{s+1}}{(s-1) !\left(s-\frac{\lambda}{\mu}\right)^{2}} \times P_{0}$

Nilai $\mathrm{L}_{\mathrm{a}}$ sebesar 0,334 artinya bahwa rata-rata pelanggan yang berada dalam antrian sebanyak 0 orang.

Rata-rata pelanggan yang antri dalam sistem $\left(\mathrm{L}_{\mathrm{s}}\right)$ rumusnya yaitu :

$\mathrm{L}_{\mathrm{s}}=\mathrm{L}_{\mathrm{a}}+\frac{\lambda}{\mu}$

Nilai $L_{s}$ sebesar 1,236 berarti bahwa rata-rata pelanggan yang berada dalam sistem antrian sebanyak 1 orang.

Rata-rata waktu menunggu dalam antrian $\left(\mathrm{W}_{\mathrm{a}}\right)$ rumusnya yaitu :

$\mathrm{W}_{\mathrm{a}}=\frac{\left(\frac{\lambda}{\mu}\right)^{\mathrm{s}+1}}{\lambda(\mathrm{s}-1) !\left(\mathrm{s}-\frac{\lambda}{\mu}\right)^{2}} \times \mathrm{P}_{0}$

Nilai $\mathrm{W}_{\mathrm{a}}$ sebesar 17,32 detik menunjukkan rata-rata yang dihabiskan seorang pelanggan dalam antrian adalah $\pm 0,289$ menit.

Rata-rata waktu menunggu dalam sistem $\left(\mathrm{W}_{\mathrm{s}}\right)$ rumusnya yaitu :

$\mathrm{W}_{\mathrm{s}}=\mathrm{W}_{\mathrm{a}}+\frac{1}{\mu}$

Nilai $\mathrm{W}_{\mathrm{s}}$ sebesar 64,05 detik menunjukkan waktu rata-rata yang dihabiskan seorang pelanggan dalam sistem antrian adalah \pm sebesar 1 menit.

* Tingkat kesibukan server $(\mathrm{K})$ rumusnya Yaitu sebagai berikut :

$\mathrm{K}=\frac{\lambda}{\mathrm{s} . \mu}$

Tingkat kesibukan server adalah $\pm 45 \%$ dapat dikatakan bahwa seorang server tidak terlalu sibuk dalam melayani pelanggannya.

* Tingkat pengangguran server (W) rumusnya yaitu sebagai berikut :

$W=100 \%-K$ 
Tingkat pengangguran server yang diperoleh \pm sebesar $55 \%$. Dapat dikatakan bahwa seorang server memiliki banyak waktu senggang.

Waktu rata-rata menunggu seorang pelanggan yang diperoleh untuk penambahan satu server cukup jauh berbeda dari waktu rata-rata pelanggan sebelum dilakukan penambahan satu unit server untuk rata-rata waktu menunggu pelanggan dalam antrian menjadi berkurang dari 7 menit menjadi 0,289 menit. Analisis biaya untuk penambahan satu unit server akan dihitung berdasarkan hasil yang telah diperoleh pada analisis model antrian jalur tunggal, satu tahap pelayanan yaitu sebagai berikut :

- Total biaya menunggu yaitu sebagai berikut :

Dik : Gaji Server untuk 2 orang server = Rp. 3.500 .000

$\mathrm{n}_{\mathrm{t}} \quad=60$ orang

$\mathrm{c}_{\mathrm{w}} \quad=$ Rp. 1.925 .000

Total biaya menunggu $=\mathrm{E}\left(\mathrm{C}_{\mathrm{w}}\right)=\mathrm{n}_{\mathrm{t}} \mathrm{Xc}_{\mathrm{w}}=$ Rp. 115.500 .000

- Total biaya pelayanan yaitu sebagai berikut

Dik : Biaya pembuatan satu server $=$ Rp. 150.000.000.

$\mathrm{s}=2$ unit server

$\mathrm{C}_{\mathrm{s}}=$ Rp. 153.500 .000

Total biaya pelayanan $\mathrm{E}\left(\mathrm{C}_{\mathrm{s}}\right)=\mathrm{s} \times\left(\mathrm{C}_{\mathrm{s}}\right)=\mathrm{Rp} .307 .000 .00,00$

- Total biaya keseluruhan sebagai berikut :

$\mathrm{E}\left(\mathrm{C}_{\mathrm{t}}\right)=\mathrm{E}\left(\mathrm{C}_{\mathrm{w}}\right)+\mathrm{E}\left(\mathrm{C}_{\mathrm{s}}\right)=$ Rp. $422.500 .000,00$

Jadi total biaya operasional SPBU I Gusti Ngurahrai Palu khususnya dibagian pengisian bahan bakar dengan jenis bahan bakar Premium dengan menggunakan 2 unit server adalah sebesar Rp. 422.500.000,00. Dengan total biaya seperti ini proses antrian yang terjadi dapat dikurangi dan pelayannya menjadi optimal.

\section{KESIMPULAN}

Berdasarkan hasil penelitian dan pembahasan yang diperoleh, dapat diambil beberapa kesimpulan sebagai berikut:

1. Karakteristik antrian dari model antrian jalur tunggal dengan satu tahap pelayanan di SPBU I Gusti Ngurahrai Palu yang diperoleh selama penelitian menunjukkan bahwa :

- Rata-rata yang antri dalam sistem $\left(L_{s}\right)$ adalah 9,19 atau \pm sebesar 9 orang.

- Rata-rata yang antri dalam antrian $\left(L_{a}\right)$ adalah 8,23 atau sebesar 8 Orang. 
- Peluang terjadinya jumlah konsumen dalam antrian $\left(\mathrm{P}_{\mathrm{n}}\right)$ adalah sebesar 0,0421 atau dengan kata lain sebesar $4,21 \%$.

- Rata-rata waktu menunggu dalam sistem $\left(\mathrm{W}_{\mathrm{s}}\right)$ adalah sebesar 476,19 detik atau \pm 8 menit.

- Rata-rata waktu menunggu dalam antrian $\left(\mathrm{W}_{\mathrm{a}}\right)$ adalah sebesar 429,46 detik atau \pm 7 menit

- Tingkat Kesibukan server $(\mathrm{K})$ adalah \pm sebesar $90,18 \%$

- Tingkat pengangguran server adalah \pm sebesar $9,82 \% \approx 10 \%$

2. Biaya Operasional yang harus dikeluarkan oleh pihak SPBU I Gusti Nguragrai Palu dengan adanya satu unit Server dibagian jenis bahan bakar premium khususnya untuk pengendara bermotor yaitu sebesar Rp. 246.250.000,00 dan waktu menunggu untuk dilayani sebesar \pm 7 menit, sehingga pelanggan merasa tidak nyaman dalam proses antrian pengisian bahan bakar. Jika dilakukan penambahan satu unit server biaya operasional yang harus dikeluarkan adalah Rp. 422.500.000,00 dan waktu menunggu untuk dilayani sebesar $\pm 0,289$ menit, tetapi pelanggan merasa nyaman tanpa harus menunggu lama untuk dilayani.

\section{DAFTAR PUSTAKA}

[1] Kakiav, T.J., 2004, Dasar Teori Antrian untuk Kehidupan Nyata, Andi, Yogyakarta.

[2] Subagyo, P. Dkk., 2000, Dasar-dasar Operation Research, BPFE, Yogyakarta.

[3] Djarwanto, 1995, Statistik Nonparametrik, BPFE, Surakarta. 